\title{
Correlates and outcomes of preterm birth, low birth weight, and small for gestational age in HIV-exposed uninfected infants
}

Jennifer A Slyker ${ }^{1 * \dagger}$, Janna Patterson ${ }^{2 \dagger}$, Gwen Ambler ${ }^{3}$, Barbra A Richardson ${ }^{1,4}$, Elizabeth Maleche-Obimbo ${ }^{6}$, Rose Bosire $^{6}$, Dorothy Mbori-Ngacha ${ }^{6}$, Carey Farquhar ${ }^{1,3,5}$ and Grace John-Stewart ${ }^{1,2,3,5}$

\begin{abstract}
Background: Preterm birth (PTB), low birth weight (LBW) and small for gestational age (SGA) contribute to neonatal mortality. Maternal HIV-1 infection has been associated with an increased risk of PTB, but mechanisms underlying this association are undefined. We describe correlates and outcomes of PTB, LBW, and SGA in HIV-exposed uninfected infants.

Methods: This was a retrospective analysis of cohort study. Between 1999-2002, pregnant, HIV-infected women were enrolled into an HIV-1 transmission study. Logistic regression was used to identify correlates of PTB, LBW and SGA in HIV-negative, spontaneous singleton deliveries. Associations between birth outcomes and mortality were measured using survival analyses.

Results: In multivariable models, maternal plasma $(\mathrm{OR}=2.1,95 \% \mathrm{Cl}=1.1-3.8)$ and cervical HIV-1 RNA levels (OR= $1.6,95 \% \mathrm{Cl}=1.1-2.4)$, and $\mathrm{CD} 4<15 \%(\mathrm{OR}=2.4,95 \% \mathrm{Cl}=1.0-5.6)$ were associated with increased odds of PTB.

Abnormal vaginal discharge and cervical polymorphonuclear leukocytes were also associated with PTB. Cervical HIV-1 RNA level $(\mathrm{OR}=2.4,95 \% \mathrm{Cl}=1.5-6.7)$ was associated with an increased odds of LBW, while increasing parity $(\mathrm{OR}=0.46,95 \% \mathrm{Cl}=0.24-0.88)$ was associated with reduced odds. Higher maternal body mass index $(\mathrm{OR}=0.75$, $95 \% \mathrm{Cl}=0.61-0.92)$ was associated with a reduced odds of SGA, while bacterial vaginosis was associated with $>3$-fold increased odds $(\mathrm{OR}=3.2,95 \% \mathrm{Cl}=1.4-7.4)$. PTB, LBW, and SGA were each associated with a $>6$-fold increased risk of neonatal death, and a $>2$-fold increased rate of infant mortality within the first year.
\end{abstract}

Conclusions: Maternal plasma and cervical HIV-1 RNA load, and genital infections may be important risk factors for PTB in HIV-exposed uninfected infants. PTB, LBW, and SGA are associated with increased neonatal and infant mortality in HIV-exposed uninfected infants.

Keywords: Preterm birth, Low birth weight, Small for gestational age, Pediatric HIV

\section{Background}

Globally, it is estimated that there are more than 13 million preterm births (PTB) annually, comprising $11 \%$ of live births, with the highest burden in low-income countries $[1,2]$. PTB is both a direct and indirect leading cause of mortality in the neonatal period, accounting for $28 \%$ of global neonatal deaths [3]. Low birth weight

\footnotetext{
* Correspondence: jslyker@uw.edu

${ }^{\dagger}$ Equal contributors

'Department of Global Health, University of Washington, Harborview Medical Center, 325 9th Ave, Box 359931, Seattle, WA 98104, USA

Full list of author information is available at the end of the article
}

(LBW) and small for gestational age (SGA) newborns are also at elevated risk for death (reviewed in [4]). Beyond the neonatal period, preterm infants are at an increased risk of morbidity and mortality, developmental delays, lower educational attainment, and increased lifetime risk of non-communicable diseases [5].

Mechanisms resulting in PTB are not fully understood. Maternal infection, and vaginal infection in particular, is thought to be a major pathway to PTB [6,7]. Markers of inflammation and infection have been associated with PTB, and treatment for some vaginal infections has been shown to reduce the rates of PTB $[7,8]$. To date, a

\section{Biomed Central}

(c) 2014 Slyker et al.; licensee BioMed Central Ltd. This is an open access article distributed under the terms of the Creative Commons Attribution License (http://creativecommons.org/licenses/by/2.0), which permits unrestricted use, distribution, and reproduction in any medium, provided the original work is properly cited. 
handful of studies have examined correlates of adverse birth outcomes in the setting of maternal HIV-1 infection, with variable findings. Maternal plasma HIV-1 RNA load, CD4 counts and symptomatic disease have been associated with PTB in some studies but not others [9-11]. Differences in sociodemographics, behavior, genetics, vaginal flora, co-infections, secular time, and delivery inclusion/exclusion criteria (gestational age cutoff, elective caesarean sections and twins), undoubtedly result in confounding, which could attenuate observed associations with PTB.

Maternal antiretroviral therapy (ART) for either prevention of mother to child transmission (PMTCT) or treatment has introduced further complexity to discerning relationships between HIV-1 and birth outcomes. The risk of PTB declined in HIV-infected women during the period between 1989-2004 in the United States [12], in contrast to increasing rates of PTB in the general population during the same period [13], suggesting that virologic suppression and/or immune reconstitution likely improves birth outcomes on the whole. However, some studies have shown differences in PTB rates by maternal ART regimen, protease-inhibitor use, or timing of ART initiation, suggesting specific drugs, or drug classes may increase the risk of PTB $[14,15]$. Current evidence suggests the use of protease-inhibitor (PI)based regimens may increase the risk of PTB over that of non-PI-based regimens [16,17].

As ART use expands in sub-Saharan Africa, the population of HIV-1 exposed uninfected infants continues to grow. HIV-exposed uninfected infants have increased rates of morbidity and mortality compared to unexposed infants (reviewed in [18]). The reason for increased morbidity among HIV-exposed uninfected infants is likely due to a combination of factors including reduced maternal transfer of antibodies, increased exposure to infectious pathogens from their mother, and altered immunologic development. Studies to better understand the vulnerability of HIV-exposed uninfected children will enable the development of strategic interventions to optimize outcomes in this unique population. Utilizing data from an historic perinatal cohort, we estimated the incidence of PTB, LBW, and SGA in a cohort of HIV-infected women and their uninfected infants. We additionally determined correlates of PTB, LBW and SGA; and quantified their association with infant mortality during the first year of life.

\section{Methods}

\section{Study population}

Protocols were approved by the Institutional Review Board of the University of Washington and the Ethics and Research Committee of Kenyatta National Hospital. HIV-infected women with gestation $\geq 28$ weeks were recruited from Nairobi antenatal clinics from 19992002 [19]. Fetal gestation at enrollment was estimated by a combination of last menstrual period and fundal height. Women received short-course zidovudine for PMTCT [19].

\section{Clinical assessments and follow-up}

Medical and obstetric histories were recorded at enrollment. At 32 weeks, clinicians performed a pelvic examination and collected blood and genital specimens for sexually transmitted infection (STI) screening [20]. Trichomonas vaginalis was diagnosed from vaginal swabs by in-pouch culture testing using the APTIMA platform (Gen-Probe, San Diego, California). Cervical swabs were used for Neisseria gonorrhoeae and Chlamydia trachomatis testing using the Amplicor CT/NG test (Roche Molecular Systems Inc, Branchburg, New Jersey). Treponema pallidum was diagnosed by the rapid plasma reagin test (Becton and Dickinson, Franklin Lakes, New Jersey) with confirmation by Treponema pallidum haemagglutination assay (Randox Laboratories Ltd, Crumlin, UK). Bacterial vaginosis (BV) was diagnosed using Nugent criteria from Gram-stained vaginal smears and Candida was identified by visualization of vaginal wet mount. Sexually transmitted and vaginal infections were treated as indicated. Mothers returned monthly for interviews and clinical assessments.

Neonates were examined at birth by a study physician. For deliveries outside the study site, birth weight data was abstracted from facility records or governmentissued mother-child health booklets. Infant gestational age at birth was assessed via Dubowitz scoring [21]. In the absence of Dubowitz, last menstrual period was used to estimate gestational age for overall incidence estimates. Mother-infant pairs attended monthly visits in the clinic for one year. For deceased infants, age at death was determined by a physician following a chart review and/or verbal autopsy with the parent or guardian $[19,22]$.

\section{Definitions}

Infants were considered preterm births (PTB) if born before 37 weeks. Low birth-weight (LBW) was defined as less than $2.5 \mathrm{~kg}$. To account for early neonatal weight loss, weight data were only included from infants weighed within 24 hours of birth. Similarly, analysis of Dubowitz assessments was restricted to those conducted within 3 days of birth. Small for gestational age (SGA) was determined via the method outlined by Mikolajczyk [23] utilizing the mean birth weight at 40 weeks in our cohort and the standard deviation specific to our sample, and using Dubowitz-estimated gestational age. Neonatal and infant mortality were defined as deaths 
occurring within the first 28 days, and 365 days of life, respectively.

\section{HIV-1 testing and viral loads}

HIV-1 RNA loads were measured using the GenProbe assay [24] in plasma and cervical swabs at 32 weeks, and in maternal plasma at delivery. HIV-1 testing was performed on infant blood at birth ( $<48$ hours) and 1, 3, 6, 9 and 12 months. Infant HIV-1 infection was defined by the detection of HIV-1 DNA in dried blood spots [25] or RNA in plasma [24]. Uninfected infants received a confirmatory HIV-1 ELISA at study exit.

\section{Statistical methods}

Stata SE v11.2 for Macintosh (StataCorp, College Station, Texas) was used for all analyses. All tests were two-tailed with alpha $=0.05$. Overall estimates of PTB rates included deliveries where either Dubowitz or last menstrual period was available. Fisher's exact test was used to compare the proportion of PTBs between infants with and without HIV-1 detection at birth.

Analyses for correlates of adverse birth outcomes and mortality were limited to spontaneous deliveries of singleton, HIV-uninfected infants. We excluded twins $(\mathrm{n}=7$ sets), planned cesarean sections $(\mathrm{n}=20)$, infants who were HIV-infected at birth $(\mathrm{n}=29)$, and those who lacked an HIV-1 test at birth (1 intrapartum death and 7 stillbirths). When analyzing correlates of PTB, we used only infants with Dubowitz assessment, because this method is more reliable than last menstrual period when compared to ultrasound [26].

Logistic regression was used to identify correlates of PTB, LBW and SGA. Covariates included a priori defined variables based on literature review and hypothesized relationships between maternal HIV-1 and birth outcome. In order to generate meaningful estimates, we required a minimum of 10 exposures for each covariate included in regression models; for this reason several welldefined risk factors (smoking, pre-eclampsia, eclampsia, Neisseria gonorrhoeae) were not evaluated because they were uncommon in this cohort (numbers are provided in Table 1). We used stepwise logistic regression to create final multivariable models; for each of the three outcomes we included all covariates with $\mathrm{p}$ values $\leq 0.1$, then performed backward elimination of covariates until we had a best-fit model. Pearson's correlation was used to measure the correlation between plasma and cervical HIV-1 RNA loads; these terms were collinear so they were not included together in any multivariable models and we present alternative models including each separately. Similarly, we made separate models for either viral load or CD4 because these terms were also collinear. In multivariable analyses, we elected to adjust for CD4 percent as an indicator of immunosuppression, rather than CD4 count, because CD4 percent is not affected by increasing blood volume during pregnancy, which causes a decline in CD4 cells $/ \mathrm{mm}^{3}$.

Mortality rates are reported separately for the neonatal (28 day) and infant (365 day) periods. All spontaneouslydelivered infants born HIV-negative were considered at risk from birth; we excluded from this analysis infants who acquired HIV-1 later during follow-up. KaplanMeier survival analysis was used to estimate the neonatal mortality incidence rate; surviving children were censored at 28 days. For infant mortality, individuals were censored at study exit, or 1 year, whichever came first. Cox proportional hazards regression was used to estimate hazard ratios (HR) for PTB, LBW, and SGA, individually, and adjusted for maternal plasma HIV-1 RNA load at 32 weeks gestation, with censoring at study exit or 1 year, whichever came first. Kaplan-Meier survival plots with the log-rank statistic are provided to illustrate differences between mortality in the different groups over time.

\section{Results}

Overall rate of preterm birth

A total of 475 women delivered 482 infants. Gestational age was estimated using Dubowitz (385 women) or last menstrual period ( 80 women) in 465 women. The overall PTB rate was $14 \%(65 / 465)$. PTB comprised $28 \%$ $(8 / 29)$ of deliveries of HIV-infected infants (inclusive of 2 twin deliveries), and 13\% (57/429) of HIV-uninfected infants (inclusive of 5 twin deliveries, $\mathrm{p}=0.05$ ).

\section{Participant characteristics}

A total of 413 women spontaneously delivered live, singleton infants who were HIV-negative at birth (Figure 1); 332 infants (80\%) had weight assessed within the first day, 335 (81\%) had Dubowitz assessed within 3 days, and 311 (75\%) had both Dubowitz and weight assessed within the specified time limits enabling calculation of SGA. Of the 413 infants born HIV-negative, 54 (13\%) later acquired HIV-1.

Characteristics of the women who spontaneously delivered live, singleton HIV-negative infants are detailed in Table 1. Most mothers were young and married. The majority of deliveries occurred at the study site, Kenyatta National Hospital (85\%). Cigarette smoking alcohol use, pre-eclampsia and eclampsia were rare. Vaginal infections were common; $37 \%$ of women had BV, 30\% had Candida, and $21 \%$ had a laboratory-confirmed STI at 32 weeks gestation.

\section{Rates of PTB, LBW and SGA in spontaneously delivered, singleton, HIV-uninfected infants}

There were 33 spontaneous, singleton preterm deliveries of HIV-exposed uninfected infants (9.9\%). The median gestational age of PTB infants was 35 weeks, $(\mathrm{IQR}=34-36)$. 
Table 1 Population characteristics of HIV-infected women spontaneously delivering singleton, HIV-uninfected infants

\begin{tabular}{ll}
\hline $\mathrm{N}$ & $\begin{array}{l}\text { Median (IQR) or } \\
\text { proportion (n) }\end{array}$ \\
\hline
\end{tabular}

Sociodemographic

$\begin{array}{lll}\text { Married } & 413 & 90 \%(372) \\ \text { Employed } & 413 & 30 \%(123) \\ \text { Years education } & 408 & 8(8-11)\end{array}$

Physical and Obstetric (Current pregnancy)

$\begin{array}{lll}\text { Age (years) } & 413 & 25(22-28) \\ \text { Body mass index at 32 weeks } & 400 & 24(23-26) \\ \text { Parity } & 409 & 1(1-2) \\ \text { Pre-eclampsia } & 408 & 1.5 \%(6) \\ \text { Eclampsia } & 407 & 0.25 \%(1)\end{array}$

Place of delivery

$\begin{array}{lll}\text { Kenyatta National Hospital } & 412 & 85 \%(350) \\ \text { Other facility } & 412 & 6.1 \%(25) \\ \text { Home } & 412 & 7.5 \%(31) \\ \text { En route to hospital } & 412 & 1.5 \%(6) \\ \text { sarean section } & 394 & 15 \%(58) \\ \text { hol use } & 410 & 3.9 \%(16) \\ \text { arette smoking } & 412 & 1.2 \%(5)\end{array}$

Vaginal infections at 32 weeks

Bacterial vaginosis

$38537 \%(144)$

Candida field

Cervical PMN $\geq 3$ per high-powered 336 61\% (204)

Abnormal vaginal discharge

$408 \quad 50 \%(204)$

Cervical blood

Trichomonas vaginalis

$408 \quad 4.7 \%(19)$

$408 \quad 16 \%(65)$

Chlamydia trachomatis

$407 \quad 3.9 \%(16)$

Treponema pallidum

Neisseria gonorrhoeae

Any sexually transmitted infection ${ }^{a}$

$4092.4 \%(10)$

$407 \quad 2.0 \%(8)$

$41321 \%(88)$

Immunologic and virologic

CD4 cells $/ \mathrm{mm}^{3}<350$

$40134 \%(137)$

CD4 percent $<15$

$401 \quad 15 \%(60)$

$\log _{10}$ plasma HIV-1 RNA load

$\log _{10}$ cervical HIV-1 RNA load

Cervical HIV DNA detectable

Delivery

Baby female (weeks)

Dubowitz estimated maturity $\quad 33540$ (39-41)

Premature

$3359.9 \%(33)$

$33 \quad 35(34-36)$
Table 1 Population characteristics of HIV-infected women spontaneously delivering singleton, HIV-uninfected infants (Continued)

\section{Dubowitz estimated maturity in}

preterm (weeks)

$$
\begin{aligned}
& \text { Low birth weight } \quad 3326.0 \% \text { (20) } \\
& \text { infants }(\mathrm{kg}) \\
& \text { Birth weight in low birth weight } 332 \quad 2.2(1.5-2.4)
\end{aligned}
$$

Notes. All clinical assessments and laboratory measurements were performed at 32 weeks gestation. Includes laboratory-confirmed Neisseria gonorrhoeae, Trichomonas vaginalis, Chlamydia trachomatis, and Treponema pallidum.

Of the 29 preterm infants with birth weight assessed within 24 hours, 11 (38\%) were also LBW and 3 were SGA (10\%). A total of $6.0 \%(20 / 332)$ of infants were LBW. A large proportion of LBW cases were explained by preterm delivery, $61 \%(11 / 18)$. Overall, $9.0 \%$ of infants were SGA (28/311); 11\% of these SGA infants had been born preterm.

\section{Correlates of PTB, LBW and SGA among spontaneous,} singleton HIV-negative deliveries

Maternal cervical HIV-1 RNA load (odds ratio $(\mathrm{OR})=$ 1.8, $\mathrm{p}=0.001)$, plasma HIV-1 RNA load $(\mathrm{OR}=1.9, \mathrm{p}=$ $0.02)$, and $\mathrm{CD} 4$ percent $<15(\mathrm{OR}=3.3, \mathrm{p}=0.004)$ were associated with an increased odds of PTB (Table 2). No specific STIs or genital infections were significantly associated with PTB. However, abnormal vaginal discharge $(\mathrm{OR}=2.4, \mathrm{p}=0.03)$, detection of cervical polymorphonuclear leukocytes (PMN) at a density of $\geq 3$ per highpower field (the cohort median; $O R=3.2, p=0.02$ ), and detection of blood in the cervix $(\mathrm{OR}=5.1, \mathrm{p}=0.002)$ were associated with an increased odds of PTB. There was a non-significant increased odds of PTB in women with $\mathrm{BV}$ diagnosed at 32 weeks $(\mathrm{OR}=2.1, \mathrm{p}=0.06)$.

Correlates of LBW included cervical HIV-1 replication at 32 weeks gestation; each 1-log increase in cervical HIV-1 RNA load was associated with a $>2$-fold increased odds of LBW $(\mathrm{OR}=2.1, \mathrm{p}<0.001)$. Higher maternal body mass index (BMI, OR $=0.74, \mathrm{p}=0.004)$ at 32 weeks gestation and increasing parity $(\mathrm{OR}=0.52, \mathrm{p}=0.02)$ were associated with reduced odds of LBW.

Unlike PTB and LBW, no maternal immune or virologic indicators were significantly associated with SGA. SGA was more common in female infants $(\mathrm{OR}=2.7, \mathrm{p}=$ $0.02)$, and in the presence of maternal $B V(O R=3.2, p=$ 0.005). Higher BMI at 32 weeks gestation was associated with reduced odds of SGA $(\mathrm{OR}=0.80, \mathrm{p}=0.007)$.

\section{Adjusted correlates of PTB, LBW and SGA among} spontaneous, singleton HIV-negative deliveries The odds of PTB were independently associated with cervical PMN detection $(\mathrm{OR}=2.9,95 \% \mathrm{CI}=1.2-7.3 ; \mathrm{p}=$ 


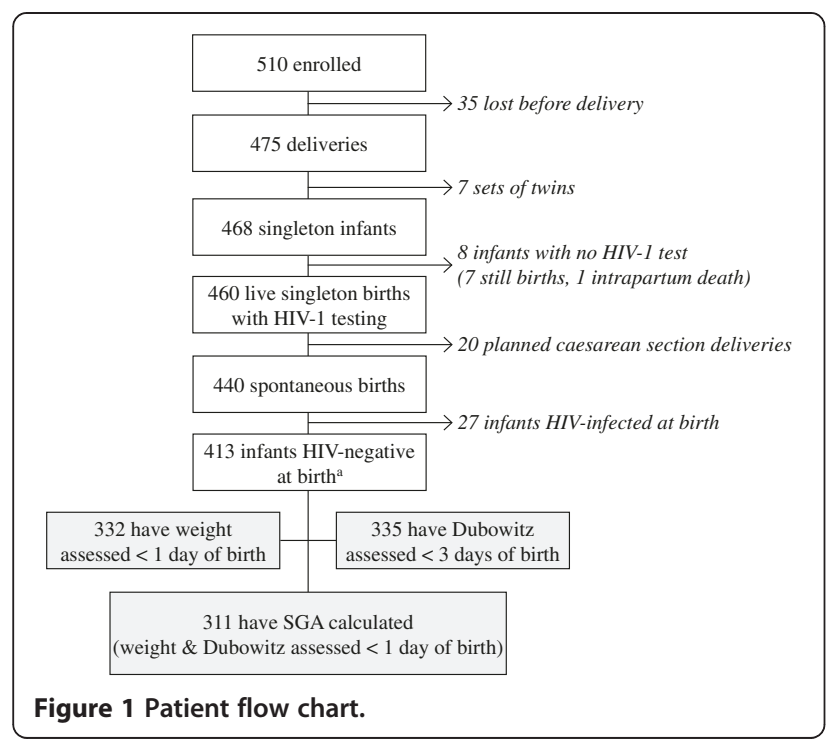

0.02; Model 1), abnormal vaginal discharge $(\mathrm{OR}=3.1$, $95 \% \mathrm{CI}=1.2-7.9 ; \mathrm{p}=0.02$; Model 1$), \log _{10}$ plasma HIV-1 RNA load $(\mathrm{OR}=2.1,95 \% \mathrm{CI}=1.1-3.8 ; \mathrm{p}=0.03$; Model 1), $\log _{10}$ cervical HIV-1 RNA load $(\mathrm{OR}=1.6,95 \% \mathrm{CI}=$ 1.1-2.4; $\mathrm{p}=0.02$; Model 2), and CD4\% less than $15 \%$ $(\mathrm{OR}=2.4,95 \% \mathrm{CI}=1.0-5.6 ; \mathrm{p}=0.05$; Model 3). The odds of LBW (Model 4) were independently associated with $\log _{10}$ plasma HIV-1 RNA load $(\mathrm{OR}=2.4,95 \% \mathrm{CI}=1.5$ 6.7; $\mathrm{p}<0.001)$, whereas each additional live birth in a woman's history was associated with reduced odds of $\mathrm{LBW}$ (OR for parity $=0.46,95 \% \mathrm{CI}=0.24-0.88 ; \mathrm{p}=0.02$ ). BV was associated with a $>3$-fold increased odds of SGA (Model 5; OR $=3.2,95 \% \mathrm{CI}=1.4-7.4 ; \mathrm{p}=0.007$ ), whereas each 1-unit increase in maternal BMI at 32 weeks gestation was associated with a $25 \%$ reduced odds of SGA $(\mathrm{OR}=0.75,95 \% \mathrm{CI}=0.61-0.92 ; \mathrm{p}=0.005)$.

\section{PTB, LBW, SGA and mortality}

From the subset of 413 infants born HIV-negative, 359 remained HIV-uninfected until study exit or death; of these 287 had Dubowitz assessed within 72 hours of birth, 287 had birth weight assessed within 24 hours of birth, and 268 had SGA evaluated (both Dubowitz and birth weight assessed in 48 hours).

A total of 32 infant deaths were recorded in the HIVexposed uninfected infants during the first year of life, and 13 occurred during the first 28 days of life. The neonatal mortality incidence rate (IR) for infants born PTB was 7 -fold higher than infants born at term (IR $=5.8$ vs 0.81 per 1000 person-days, incidence rate ratio $($ IRR $)=$ 7.1, $95 \% \mathrm{CI}=1.5-30, \mathrm{p}=0.008$ ). The neonatal mortality IR for infants born LBW was more than 6 -fold higher than infants born at normal weight $(\mathrm{IR}=6.7$ versus 1.0 per 1000 person-days, IRR $=6.4,95 \% \mathrm{CI}=1.1-27, \mathrm{p}=$ 0.02). The neonatal mortality IR for infants born SGA was 7-fold higher than infants born with normal weight for gestational age (5.4 versus 0.73 per 1000 persondays, $\mathrm{IRR}=7.4,95 \% \mathrm{CI}=1.5-34, \mathrm{p}=0.009$ ).

We also examined associations between PTB, LBW and SGA and infant survival during the first year of life. In unadjusted analyses, PTB, LBW, SGA, and maternal prenatal HIV-1 RNA load were all associated with an increased rate of infant death (Table 3 \& Figure 2). When adjusting for maternal plasma HIV-1 RNA load at 32 weeks gestation, PTB (hazard ratio $(\mathrm{HR})=2.7, \mathrm{p}=0.05$ ), LBW $(\mathrm{HR}=3.3, \mathrm{p}=0.03)$ and SGA $(\mathrm{HR}=2.9, \mathrm{p}=0.04)$ remained independently associated with time to infant death.

\section{Discussion}

This study identified several potentially modifiable factors that were associated with PTB, LBW, and SGA among HIV-exposed uninfected infants. Maternal genital infection was a predominant correlate of PTB in this cohort: cervical HIV-1 RNA load, the detection of PMN in cervical fluid, and vaginal discharge were all associated with increased odds of PTB. Cervical HIV-1 RNA load was also independently associated with an increased likelihood of delivering a LBW infant. BV and maternal BMI in pregnancy were independently associated with SGA, but HIV-1 RNA load was not. The consequences of being born preterm or small were profound; PTB, LBW and SGA were each significantly associated with $>6$-fold increased neonatal mortality rate and a $>2$ fold increased infant mortality rate. These data demonstrate that PTB, LBW, and SGA may be associated with mortality in HIV-exposed uninfected children, and suggest that reduction of maternal genital HIV-1 replication could be a strategy to reduce the risk of late preterm birth and low birth weight deliveries.

Genital infection/inflammation, as indicated by vaginal discharge and PMN in cervical swabs, emerged as important predictors of PTB and LBW in this cohort. To our knowledge, this is the first report demonstrating an association between HIV-1 RNA load in cervical fluid and PTB or LBW. Ascending infection into the uterus is one mechanism by which lower genital infections are thought to trigger PTB [27]. Additionally, the process of cervical ripening could be accelerated by HIV-induced inflammation and migration of leukocytes to infected cervical tissue. Cervicitis has been associated with PTB and/or LBW delivery in several studies [28,29], and a study by Brown and colleagues reported an association between the detection of cervical HSV-2 shedding and PTB [30]. Together, these data are consistent with the evolving model of PTB that includes maternal genital infection as a primary pathway leading to PTB (discussed in $[27,31])$. Whether any of these associations are causal in nature is beyond the scope of our study, however, they 
Table 2 Correlates of prematurity, low birth weight and small for gestational age deliveries of HIV-exposed uninfected infants

\begin{tabular}{|c|c|c|c|c|c|c|}
\hline \multirow[b]{2}{*}{ A) Univariable analysis } & \multicolumn{2}{|l|}{ Preterm } & \multicolumn{2}{|c|}{ Low birth weight } & \multicolumn{2}{|c|}{ Small for gestational age } \\
\hline & $\mathrm{OR}[95 \% \mathrm{Cl}]$ & $P$ & $\mathrm{OR}[95 \% \mathrm{Cl}]$ & $P$ & $\mathrm{OR}[95 \% \mathrm{Cl}]$ & $P$ \\
\hline Female infant & $1.1[0.53-2.3]$ & 0.8 & $2.3[0.88-5.8]$ & 0.09 & $2.7[1.2-6.2]$ & 0.02 \\
\hline Married & $1.8[0.42-8.0]$ & 0.4 & $0.65[0.18-2.3]$ & 0.5 & $0.88[0.25-3.1]$ & 0.8 \\
\hline Employed & $0.87[0.39-1.9]$ & 0.7 & $1.0[0.39-2.8]$ & 0.9 & $1.0[0.42-2.4]$ & $>0.9$ \\
\hline Years education & $0.89[0.78-1.0]$ & 0.1 & $1.1[0.94-1.3]$ & 0.2 & $1.1[0.96-1.3]$ & 0.1 \\
\hline Age (years) & $0.97[0.89-1.1]$ & 0.5 & $0.93[0.83-1.0]$ & 0.2 & $0.97[0.89-1.1]$ & 0.5 \\
\hline Body mass index & $0.90[0.78-1.0]$ & 0.1 & $0.74[0.61-0.91]$ & 0.004 & $0.80[0.68-0.94]$ & 0.007 \\
\hline Parity & $0.91[0.68-1.2]$ & 0.6 & $0.52[0.30-0.89]$ & 0.02 & $0.78[0.53-1.1]$ & 0.2 \\
\hline Alcohol use & b & & c & & $1.7[0.37-8.2]$ & 0.5 \\
\hline Bacterial vaginosis & $2.1[0.97-4.4]$ & 0.06 & $2.1[0.78-5.6]$ & 0.1 & $3.2[1.4-7.3]$ & 0.005 \\
\hline Candida & $0.90[0.40-2.0]$ & 0.8 & $1.1[0.41-3.1]$ & 0.8 & $0.74[0.30-1.8]$ & 0.5 \\
\hline Cervical PMN $\geq 3$ per high-powered field ${ }^{a}$ & $3.2[1.2-8.9]$ & 0.02 & $2.9[0.81-10]$ & 0.1 & $1.9[0.75-4.7]$ & 0.2 \\
\hline Abnormal vaginal discharge & $2.4[1.1-5.2]$ & 0.03 & $1.8[0.70-4.7]$ & 0.2 & $0.89[0.41-1.9]$ & 0.8 \\
\hline Cervical blood & $5.1[1.8-14]$ & 0.002 & $2.5[0.52-12]$ & 0.3 & $0.65[0.083-5.1]$ & 0.7 \\
\hline Trichomonas vaginalis & $0.64[0.19-2.2]$ & 0.5 & $0.32[0.042-2.5]$ & 0.3 & $0.72[0.21-2.5]$ & 0.6 \\
\hline Chlamydia trachomatis & $1.7[0.35-7.8]$ & 0.5 & $3.4[0.69-17]$ & 0.1 & $0.82[0.10-6.6]$ & 0.9 \\
\hline Treponema pallidum & b & & $1.8[0.21-15]$ & 0.6 & $1.1[0.14-9.2]$ & 0.9 \\
\hline Any sexually transmitted infection & $0.68[0.25-1.8]$ & 0.4 & $0.91[0.30-2.8]$ & 0.9 & $0.81[0.29-2.2]$ & 0.7 \\
\hline CD4 cells $/ \mathrm{mm}^{3}<350$ & $1.9[0.90-4.0]$ & 0.09 & $2.0[0.79-5.3]$ & 0.1 & $1.1[0.50-2.5]$ & 0.8 \\
\hline CD4 percent $<15$ & $3.3[1.4-7.7]$ & 0.004 & $1.8[0.58-5.9]$ & 0.3 & $1.0[0.33-3.1]$ & $>0.9$ \\
\hline $\log _{10}$ HIV plasma HIV-1 RNA load at 32 weeks & $1.9[1.1-3.1]$ & 0.02 & $1.5[0.81-2.9]$ & 0.2 & $1.1[0.69-1.8]$ & 0.7 \\
\hline \multirow[t]{2}{*}{$\log _{10}$ HIV cervical HIV-1 RNA load at 32 weeks } & $1.8[1.3-2.5]$ & 0.001 & $2.1[1.4-3.2]$ & $<0.001$ & $1.3[0.88-1.8]$ & 0.2 \\
\hline & \multicolumn{2}{|l|}{ Preterm } & \multicolumn{2}{|c|}{ Low birth weight } & \multicolumn{2}{|c|}{ Small for gestational age } \\
\hline B) Multivariable analyses & $\mathrm{OR}[95 \% \mathrm{Cl}]$ & P & $\mathrm{OR}[95 \% \mathrm{Cl}]$ & P & OR $[95 \% \mathrm{Cl}]$ & P \\
\hline \multicolumn{7}{|l|}{ Model 1 (includes plasma HIV-1 RNA load) } \\
\hline Cervical PMN $\geq 3$ per high-powered field & $2.9[1.2-7.3]$ & 0.02 & * & & * & \\
\hline Abnormal vaginal discharge & $3.1[1.2-7.9]$ & 0.02 & * & & * & \\
\hline $\log _{10}$ HIV plasma HIV-1 RNA load & $2.1[1.1-3.8]$ & 0.03 & * & & * & \\
\hline \multicolumn{7}{|l|}{ Model 2 (includes cervical HIV-1 RNA load) } \\
\hline Cervical PMN $\geq 3$ per high-powered field & $2.7[1.0-7.3]$ & 0.05 & * & & * & \\
\hline Abnormal vaginal discharge & $3.6[1.2-10]$ & 0.02 & * & & * & \\
\hline $\log _{10}$ HIV cervical HIV-1 RNA load & $1.6[1.1-2.4]$ & 0.02 & * & & * & \\
\hline
\end{tabular}


Table 2 Correlates of prematurity, low birth weight and small for gestational age deliveries of HIV-exposed uninfected infants (Continued)

Model 3 (includes CD4 percent $<15)^{d}$

Cervical PMN $\geq 3$ per high-powered field

3.5 [1.4-8.6]

$3.2[1.3-8.2]$

Abnormal vaginal discharge

$2.4[1.0-5.6]$

0.007

CD4 percent $<15$

0.01

Model 4

Parity

Log $_{10}$ HIV cervical HIV-1 RNA load

Model 5

Body mass index

$*$

$0.46[0.24-0.88]$

0.02

$2.4[1.5-6.7]$

$<0.001$

*

$0.75[0.61-0.92]$

0.005

Notes. All clinical assessments and laboratory measurements were performed at 32 weeks gestation. ${ }^{a}$ Cohort median for polymorphonuclear cells (PMN) detected was $3 .{ }^{b}$ No women who used alcohol during pregnancy, and no women with Treponema pallidum delivered preterm. ' No women who used alcohol during pregnancy delivered a low birth weight infant. B) Multivariable logistic regression models. Stepwise

logistic regression was used to create final multivariable models for each of the three outcomes as described in the Statistical Methods; because plasma HIV viral load, cervical HIV viral load, and CD4 percent were

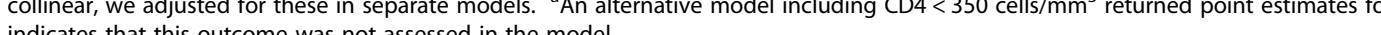

indicates that this outcome was not assessed in the model. 
Table 3 Correlates of infant mortality during 12-month follow-up

\begin{tabular}{|c|c|c|c|c|c|c|}
\hline & \multicolumn{3}{|c|}{ Unadjusted } & \multicolumn{3}{|c|}{ Adjusted for maternal plasma HIV-1 RNA load } \\
\hline & $\mathbf{N}$ & $\mathrm{HR}[95 \% \mathrm{Cl}]$ & $P$ value & $\mathbf{N}$ & aHR $[95 \% \mathrm{Cl}]$ & $P$ value \\
\hline Preterm birth & 287 & $3.9[1.5-10]$ & 0.004 & 275 & $2.7[1.0-7.5]^{b}$ & 0.05 \\
\hline Low birth weight & 287 & $4.5[1.7-12]$ & 0.003 & 277 & $3.3[1.1-10]^{c}$ & 0.03 \\
\hline Small for gestational age & 268 & $3.0[1.1-8.1]$ & 0.03 & 258 & $2.9[1.0-8.0]^{\mathrm{d}}$ & 0.04 \\
\hline Maternal $\log _{10}$ HIV plasma HIV-1 RNA load ${ }^{a}$ & 342 & $1.8[1.1-2.9]$ & 0.03 & & $b, c, d$ & \\
\hline
\end{tabular}

Notes. Includes only children remaining HIV-uninfected throughout follow-up. Cox regression, censored at 1 year. Each outcome was adjusted separately for maternal $\log _{10}$ plasma HIV-1 RNA load. ${ }^{a}$ Viral load measured at 32 weeks gestation. ${ }^{b}$ aHR $=1.6, p=0.2$ for HIV-1 RNA load. ${ }^{c}$ aHR $=1.2, p=0.5$ for HIV-1 RNA load. $\mathrm{d}_{\mathrm{aHR}}=1.4, \mathrm{p}=0.3$ for HIV-1 RNA load.

point toward reduction of cervical infection or inflammation as potential interventions to reduce the risk of PTB.

The overall rate of PTB (14\%) in this cohort of HIVinfected women was similar to general population estimates for Kenya in 2010 (10-15\% [1]). Although HIV-infected women have been shown to be at an increased risk of PTB in research studies, population rates of PTB in HIV-infected women may be counterbalanced by their overall reduced fertility and increased mortality. Additionally, because women were enrolled after 28 weeks, extremely preterm deliveries were not measured, which could explain the low rate of PTB observed in this cohort. Consistent with previous studies, we found a higher rate of PTB in infants born HIV-infected compared to those born HIV-uninfected [12,32]. Maternal HIV-1 RNA load, CD4 count, and/or advanced HIV-1 disease have been associated with PTB in previous studies $[10,11]$. Similarly, we observed independent associations between maternal plasma HIV-1 RNA load, immunosuppression and PTB. Because plasma HIV-1 RNA load, cervical HIV-1 RNA load, and immunosuppression are strongly correlated with one another, is difficult to determine the potential contribution of each to PTB.

LBW deliveries were associated with maternal weight, BMI, and parity, consistent with previous reports in both HIV-infected and uninfected populations [33,34]. In a study of HIV-infected women from Mombasa, Kenya correlates of LBW included age, education, primiparity, prior neonatal death, and delivery of a female infant [35]. Maternal HIV-1 RNA load and/or CD4 count have also been associated with LBW, intrauterine growth restriction, or SGA $[9,11,34]$. In our multivariable analyses, only parity and cervical HIV-1 RNA load were independently associated with LBW. The association between LBW and cervical HIV-1 RNA load could be explained by the large degree of overlap between PTB and LBW infants; this is somewhat supported by the observation that SGA was not associated with any maternal virologic indicators. SGA was associated with delivery of a female infant, BMI, and BV, which is consistent with previous studies in HIV-negative women [36,37].

Globally, PTBs account for the majority of deaths in the neonatal period [3]. A recent meta-analysis of studies in East Africa reported high odds ratios for death before 28 days for PTB $(\mathrm{OR}=6.2)$, moderate $\mathrm{LBW}(\mathrm{OR}=6.2)$, and SGA (2.1) compared to normal infants [38]. Similarly, neonatal mortality rates were at least 6-fold higher for PTB, LBW, and SGA infants in our study. Among HIV-exposed uninfected infants who escaped postnatal infection, PTB, LBW, and SGA delivery were also associated with an increased risk of infant mortality during the first year of life. Causes of death in the HIV-exposed uninfected infants from this cohort have been detailed elsewhere [22]; most commonly involved were sepsis, pneumonia and failure to thrive.

Our study has many strengths and some limitations. Weight, gestation, and mortality were systematically

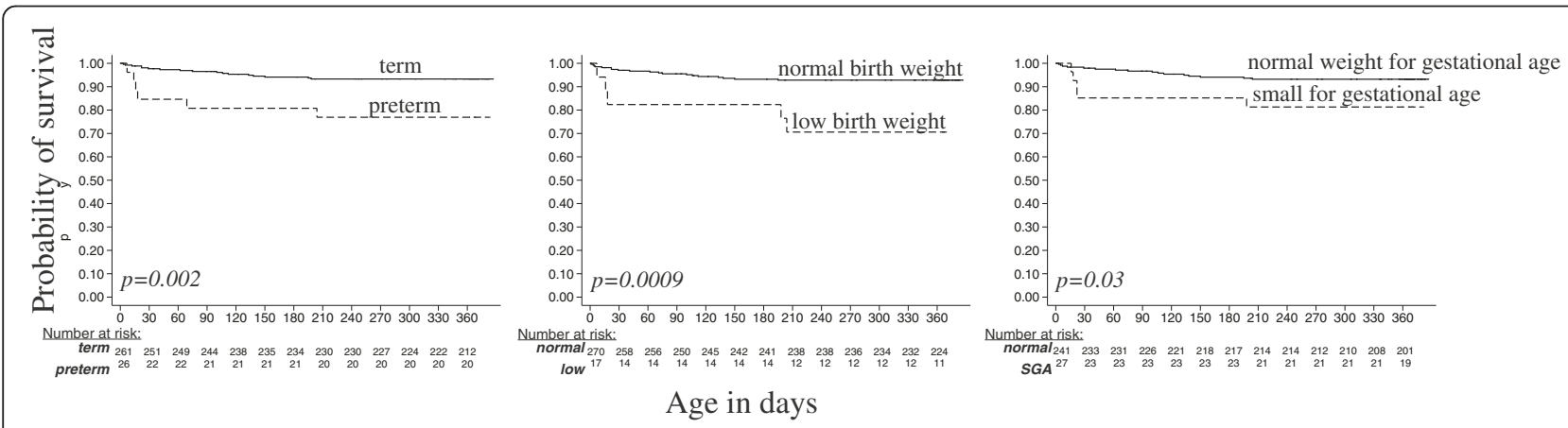

Figure 2 Survival of preterm, low birth weight, and small for gestational age HIV-exposed uninfected infants. Curves show survival functions for infants grouped by prematurity, low birth weight, and small for gestational age. P values are from log-rank test. 
assessed. Most deliveries occurred at a facility, and Dubowitz assessments of gestational age were conducted by physicians. Since the goal of our study was to identify modifiable maternal factors that could be targeted to reduce the risk of PTB and LBW deliveries, we limited analyses to spontaneous, singleton deliveries of HIVuninfected infants, to reduce confounding and increase sensitivity to detect virologic associations. Additionally, we only included infants with Dubowitz assessment to reduce misclassification of outcome. Although these data are a decade old, this cohort was accrued during a time when antiretroviral treatment was only rarely available in Kenya; we were therefore able to look at correlates of birth outcomes in a setting unconfounded by combination maternal antiretroviral therapy. Sociodemographic homogeneity of the cohort, and the rarity of welldefined risk factors such as smoking, drinking and illicitdrug use also reduced confounding and increased our sensitivity to detect virologic associations with birth outcomes. However, ultrasound dating was not available, limiting precision of gestational age estimates. Finally, current Option B and B-plus [39] PMTCT regimens involve maternal combination ART which may result in different PTB estimates and correlates than we observed in our setting of short-course zidovudine. As Option B-plus expands treatment to a larger population of women, it will be important to understand the effect of maternal HAART, and different HAART regimens, on the risk of adverse birth outcomes.

\section{Conclusions}

Our data support the association between maternal genital infection and preterm delivery in HIV-exposed uninfected infants. As the risks and benefits of increasingly efficacious PMTCT regimens and earlier PMTCT initiation are weighed, our data suggest that reduction of cervical viral replication could potentially reduce the risk of PTB and LBW deliveries. Additionally, HIV-exposed uninfected infants born PTB, LBW, or SGA are at an elevated risk for death during the neonatal and infant periods, and warrant heightened clinical monitoring.

\section{Competing interests}

The authors declare that they have no competing interests.

\section{Authors' contributions}

All authors have contributed to the preparation of this manuscript and have approved this final version. JAS and JP conducted the analyses and co-wrote the paper. BAR and GA contributed to study design, the statistical analysis plan, and determination of the final statistical models used. EM-O, RB, CF and DM-N developed the clinical protocols, birth outcome definitions, and executed the cohort study. GJS was PI of the project study that accrued the cohort, and participated in development of the manuscript aims, analyses, and interpretation of results.

\section{Acknowledgements}

We are grateful to the women and infants who participated in this study, and the clinical and data teams in Nairobi. We thank Dr. Julie Overbaugh,
Dana DeVange Panteleef and Sandra Emery (Fred Hutchinson Cancer Research Center) for HIV-1 diagnostics and viral loads. Finally, we would like to thank the UW Global Center for Integrated Health of Women, Adolescents and Children (Global WACh) Kizazi Working Group, for providing feedback on manuscript development.

\section{Funding source}

The cohort was funded by HD-23412 from the US National Institutes of Child Health and Disease (NICHD). JAS is supported by K01Al087369 from the National Institute of Allergy and Infectious Diseases (NIAID). EM-O was a scholar in the AIDS International Training and Research Program, (D43 TW000007) funded by the Fogarty International Center and the Office of Research on Women's Health. GJ-S is supported by K24HD054314, and CF by K24Al087399. This publication was also supported in part by the University of Washington CFAR (P30 Al027757). Its contents are solely the responsibility of the authors and do not represent the official views of the $\mathrm{NIH}$. The funding sources were not involved in the analyses or interpretation of data. None of the authors was paid to write this article by a pharmaceutical company or other agency,

\section{Conference presentation}

Presented as a poster at the $6^{\text {th }}$ IAS Conference on HIV Pathogenesis, Treatment and Prevention, Rome, Italy 2011.

\section{Author details}

'Department of Global Health, University of Washington, Harborview Medical Center, 325 9th Ave, Box 359931, Seattle, WA 98104, USA. ²Department of Pediatrics, Division of Neonatology, University of Washington, Seattle, USA. ${ }^{3}$ Department of Medicine, Division of Allergy and Infectious Diseases, University of Washington, Seattle, USA. ${ }^{4}$ Department of Biostatistics, University of Washington, Seattle, USA. ${ }^{5}$ Department of Epidemiology, University of Washington, Seattle, USA. ${ }^{6}$ Department of Paediatrics and Child Health, University of Nairobi, Nairobi, Kenya.

Received: 2 August 2013 Accepted: 3 January 2014

Published: 8 January 2014

\section{References}

1. Blencowe $H$, Cousens S, Oestergaard MZ, Chou D, Moller AB, Narwal R, Adler A, Vera Garcia C, Rohde S, Say L, et al: National, regional, and worldwide estimates of preterm birth rates in the year 2010 with time trends since 1990 for selected countries: a systematic analysis and implications. Lancet 2012, 379(9832):2162-2172.

2. Lawn JE, Gravett MG, Nunes TM, Rubens CE, Stanton C: Global report on preterm birth and stillbirth (1 of 7): definitions, description of the burden and opportunities to improve data. BMC Pregnancy Childbirth 2010, 10(Suppl 1):S1.

3. Lawn JE, Wilczynska-Ketende K, Cousens SN: Estimating the causes of 4 million neonatal deaths in the year 2000. Int J Epidemiol 2006, 35(3):706-718.

4. Lawn JE, Cousens S, Zupan J: 4 million neonatal deaths: when? Where? Why? Lancet 2005, 365(9462):891-900.

5. Saigal S, Doyle LW: An overview of mortality and sequelae of preterm birth from infancy to adulthood. Lancet 2008, 371(9608):261-269.

6. Hillier SL, Nugent RP, Eschenbach DA, Krohn MA, Gibbs RS, Martin DH Cotch MF, Edelman R, Pastorek JG 2nd, Rao AV, The Vaginal Infections and Prematurity Study Group, et al: Association between bacterial vaginosis and preterm delivery of a low-birth-weight infant. N Engl J Med 1995, 333(26):1737-1742.

7. Hitti J, Tarczy-Hornoch P, Murphy J, Hillier SL, Aura J, Eschenbach DA: Amniotic fluid infection, cytokines, and adverse outcome among infants at 34 weeks' gestation or less. Obstet Gynecol 2001, 98(6):1080-1088.

8. Subramaniam A, Abramovici A, Andrews WW, Tita AT: Antimicrobials for preterm birth prevention: an overview. Infect Dis Obstet Gynecol 2012, 2012:157159.

9. Lambert JS, Watts DH, Mofenson L, Stiehm ER, Harris DR, Bethel J, Whitehouse J, Jimenez E, Gandia J, Scott G, Pediatric AIDS Clinical Trials Group 185 Team, et al: Risk factors for preterm birth, low birth weight, and intrauterine growth retardation in infants born to HIV-infected pregnant women receiving zidovudine. AIDS 2000, 14(10):1389-1399.

10. Ezechi OC, David AN, Gab-Okafor CV, Ohwodo H, Oladele DA, Kalejaiye OO, Ezeobi PM, Gbajabiamila TA, Adu RA, Oke B, et al: Incidence of and 
socio-biologic risk factors for spontaneous preterm birth in HIV positive Nigerian women. BMC Pregnancy Childbirth 2012, 12:93.

11. Stratton P, Tuomala RE, Abboud R, Rodriguez E, Rich K, Pitt J, Diaz C, Hammill H, Minkoff H: Obstetric and newborn outcomes in a cohort of HIV-infected pregnant women: a report of the women and infants transmission study. J Acquir Immune Defic Syndr Hum Retrovirol 1999, 20(2):179-186.

12. Schulte J, Dominguez K, Sukalac T, Bohannon B, Fowler MG: Declines in low birth weight and preterm birth among infants who were born to HIV-infected women during an era of increased use of maternal antiretroviral drugs: pediatric spectrum of HIV disease, 1989-2004. Pediatrics 2007, 119(4):e900-906

13. Martin JA, Hamilton BE, Sutton PD, Ventura SJ, Menacker F, Kirmeyer S: Births: final data for 2004. Natl Vital Stat Rep 2006, 55(1):1-101.

14. Townsend CL, Cortina-Borja M, Peckham CS, Tookey PA: Antiretroviral therapy and premature delivery in diagnosed HIV-infected women in the United Kingdom and Ireland. AIDS 2007, 21(8):1019-1026.

15. European Collaborative Study: Swiss mother and child HIV cohort study. AIDS 2000, 14(18):2913-2920.

16. Powis KM, Kitch D, Ogwu A, Hughes MD, Lockman S, Leidner J, van Widenfelt E, Moffat C, Moyo S, Makhema J, et al: Increased risk of preterm delivery among HIV-infected women randomized to protease versus nucleoside reverse transcriptase inhibitor-based HAART during pregnancy. $J$ Infect Dis 2011, 204(4):506-514.

17. Kourtis AP, Schmid CH, Jamieson DJ, Lau J: Use of antiretroviral therapy in pregnant HIV-infected women and the risk of premature delivery: a meta-analysis. AIDS 2007, 21(5):607-615.

18. Filteau S: The HIV-exposed, uninfected African child. Trop Med Int Health 2009, 14(3):276-287.

19. Obimbo EM, Mbori-Ngacha DA, Ochieng JO, Richardson BA, Otieno PA, Bosire R, Farquhar C, Overbaugh J, John-Stewart GC: Predictors of early mortality in a cohort of human immunodeficiency virus type 1-infected african children. Pediatr Infect Dis J 2004, 23(6):536-543.

20. Marx G, John-Stewart G, Bosire R, Wamalwa D, Otieno P, Farquhar C: Diagnosis of sexually transmitted infections and bacterial vaginosis among HIV-1-infected pregnant women in Nairobi. Int J STD AIDS 2010, 21(8):549-552.

21. Dubowitz LM, Dubowitz V, Goldberg C: Clinical assessment of gestational age in the newborn infant. J Pediatr 1970, 77(1):1-10.

22. Gichuhi C, Obimbo E, Mbori-Ngacha D, Mwatha A, Otieno P, Farquhar C, Wariua G, Wamalwa D, Bosire R, John-Stewart G: Predictors of mortality in HIV-1 exposed uninfected post-neonatal infants at the Kenyatta National Hospital, Nairobi. East Afr Med J 2005, 82(9):447-451.

23. Mikolajczyk RT, Zhang J, Betran AP, Souza JP, Mori R, Gulmezoglu AM, Merialdi M: A global reference for fetal-weight and birthweight percentiles. Lancet 2011, 377(9780):1855-1861.

24. Emery S, Bodrug S, Richardson BA, Giachetti C, Bott MA, Panteleeff D, Jagodzinski LL, Michael NL, Nduati R, Bwayo J, et al: Evaluation of performance of the Gen-Probe human immunodeficiency virus type 1 viral load assay using primary subtype $A, C$, and D isolates from Kenya. J Clin Microbiol 2000, 38(7):2688-2695.

25. DeVange Panteleeff D, Emery S, Richardson BA, Rousseau C, Benki S, Bodrug S, Kreiss JK, Overbaugh J: Validation of performance of the gen-probe human immunodeficiency virus type 1 viral load assay with genital swabs and breast milk samples. J Clin Microbiol 2002, 40(11):3929-3937.

26. Rosenberg RE, Ahmed AS, Ahmed S, Saha SK, Chowdhury MA, Black RE, Santosham M, Darmstadt GL: Determining gestational age in a low-resource setting: validity of last menstrual period. J Health Popul Nutr 2009, 27(3):332-338.

27. Moodley $P$, Sturm AW: Sexually transmitted infections, adverse pregnancy outcome and neonatal infection. Semin Neonatol 2000, 5(3):255-269.

28. Nugent RP, Hillier SL, The Investigators of the Johns Hopkins Study of Cervicitis and Adverse Pregnancy Outcome: Mucopurulent cervicitis as a predictor of chlamydial infection and adverse pregnancy outcome. Sex Transm Dis 1992, 19(4):198-202.

29. Hitti J, Garcia P, Totten P, Paul K, Astete S, Holmes KK: Correlates of cervical mycoplasma genitalium and risk of preterm birth among peruvian women. Sex Transm Dis 2010, 37(2):81-85.

30. Brown ZA, Benedetti J, Selke S, Ashley R, Watts DH, Corey L: Asymptomatic maternal shedding of herpes simplex virus at the onset of labor: relationship to preterm labor. Obstet Gynecol 1996, 87(4):483-488.
31. Gravett MG, Rubens CE, Nunes TM: Global report on preterm birth and stillbirth (2 of 7): discovery science. BMC Pregnancy Childbirth 2010, 10(Suppl 1):S2

32. Abrams E, Matheson PB, Thomas PA, Thea DM, Krasinski K, Lambert G, Shaffer N, Bamji M, Hutson D, Grimm K, New York City Perinatal HIV Transmission Collaborative Study Group, et al: Neonatal predictors of infection status and early death among 332 infants at risk of HIV-1 infection monitored prospectively from birth. Pediatrics 1995, 96(3 Pt 1):451-458.

33. Nelson $\mathrm{KB}$, Ellenberg $\mathrm{JH}$ : Predictors of low and very low birth weight and the relation of these to cerebral palsy. JAMA 1985, 254(11):1473-1479.

34. Dreyfuss ML, Msamanga GI, Spiegelman D, Hunter DJ, Urassa EJ, Hertzmark E, Fawzi UW: Determinants of low birth weight among HIV-infected pregnant women in Tanzania. Am J Clin Nutr 2001, 74(6):814-826.

35. Mwanyumba F, Claeys P, Gaillard P, Verhofstede C, Chohan V, Mandaliya K, Ndinya-Achola J, Bwayo J, Temmerman M: Correlation between maternal and infant HIV infection and low birth weight: a study in Mombasa, Kenya. J Obstet Gynaecol 2001, 21(1):27-31.

36. Thorsen P, Vogel I, Olsen J, Jeune B, Westergaard JG, Jacobsson B, Moller BR: Bacterial vaginosis in early pregnancy is associated with low birth weight and small for gestational age, but not with spontaneous preterm birth: a population-based study on Danish women. J Matern Fetal Neona 2006, 19(1):1-7.

37. McCowan L, Horgan RP: Risk factors for small for gestational age infants. Best Pract Res Clin Obstet Gynaecol 2009, 23(6):779-793.

38. Marchant T, Willey B, Katz J, Clarke S, Kariuki S, ter Kuile F, Lusingu J, Ndyomugyenyi R, Schmiegelow C, Watson-Jones D, et al: Neonatal mortality risk associated with preterm birth in East Africa, adjusted by weight for gestational age: individual participant level meta-analysis. PLoS Med 2012, 9(8):e1001292.

39. World Health Organization: Antiretroviral drugs for treating pregnant women and preventing HIV infection in infants. 2010. Available from: http://whqlibdoc.who.int/ publications/2010/9789241599818_eng.pdf.

doi:10.1186/1471-2393-14-7

Cite this article as: Slyker et al: Correlates and outcomes of preterm birth, low birth weight, and small for gestational age in HIV-exposed uninfected infants. BMC Pregnancy and Childbirth 2014 14:7.

\section{Submit your next manuscript to BioMed Central and take full advantage of:}

- Convenient online submission

- Thorough peer review

- No space constraints or color figure charges

- Immediate publication on acceptance

- Inclusion in PubMed, CAS, Scopus and Google Scholar

- Research which is freely available for redistribution 